\title{
One-Step Facile Synthesis of a Simple Hole Transport Material for Ef- ficient Perovskite Solar Cells
}

\author{
Hu Chen ${ }^{*} \dagger$, Daniel Bryant ${ }^{\ddagger} \S$, Joel Troughton ${ }^{\S}$, Mindaugas Kirkus ${ }^{\dagger}$, Marios Neophytou ${ }^{\dagger}$, Xiaohe Miao $^{\dagger}$, \\ James R. Durrant ${ }^{\ddagger, \S}$, Iain McCulloch ${ }^{\dagger, \ddagger}$ \\ ${ }^{\dagger}$ King Abdullah University of Science and Technology (KAUST), SPERC, Thuwal 23955-6900, Saudi Arabia. \\ ${ }^{\ddagger}$ Department of Chemistry and Centre for Plastic Electronics, Imperial College London, Exhibition Road, SW7 2AZ, U.K. \\ ${ }^{\S}$ SPECIFIC, College of Engineering, Swansea University, Baglan Bay Innovation and Knowledge Centre, Central Avenue, \\ Baglan, United Kingdom, SA12 7AX.
}

\begin{abstract}
A hole transporting material was designed for use in perovskite solar cells, with a facile one-step synthesis from inexpensive, commercially available reagents. The molecule comprises a central fluorinated phenyl core with pendant aryl amines, namely, 3,6-difluoro- $N^{1}, N^{1}, N^{2}, N^{2}, N^{4}, N^{4}, N^{5}, N^{5}$-octakis(4-methoxyphenyl)benzene-1,2,4,5-tetraamine (DFTAB). A power conversion efficiency of up to $10.4 \%$ was achieved in a mesoporous perovskite device architecture. The merits of a simple and potentially low cost synthetic route as well as promising performance in perovskite devices, encourages further development of this materials class as new low-cost hole transporting materials for the scale up of perovskite solar cells.
\end{abstract}

Perovskite solar cells have rapidly become candidates for large scale solar deployment, due to their low cost, ease of processing and demonstrated power conversion efficiencies (PCEs) of $>20 \%^{1-5}$. Currently the highest performing lab based devices utilise hole transport materials (HTM) within architectures comprising $\quad \mathrm{FTO}_{\mathrm{TiO}}-\mathrm{bl} / \mathrm{mp}-$ $\mathrm{TiO}_{2} /$ Perovskite/HTM, where $\mathrm{TiO}_{2}$-bl is a dense titania blocking layer, $\mathrm{mp}-\mathrm{TiO}_{2}$ is a mesoporous titania scaffold and the HTM is typically 2,2',7,7' -tetrakis $(N, N$-di-pmethoxyphenylamine)-9,9'-spirobifluorene (spiroOMeTAD) ${ }^{6}$. Spiro-OMeTAD is able to facilitate devices with high PCEs on a lab scale ${ }^{7-9}$, however its complicated synthesis and multi-step purification makes it inherently expensive and limits the potential of this material in manufacturing scale production. Additionally Spiro-OMeTAD exhibits an absorption band edge at $400 \mathrm{~nm}$, within the optical spectra of organic-inorganic perovskites, reducing device performance in tandem or reverse illuminated device architectures where light must first travel through the HTM before being absorbed by the photoactive layers.

Recently there have been several new classes of HTMs designed as alternatives to spiro-OMeTAD ${ }^{10-14}$. Most research has focused on HTMs with improved optical and transport properties, however for scaleability, criteria such as reducing the synthesis steps, using less expensive pre-cursors and an ability to be produced in larger volumes, is also necessary. Additionally, ionic additives or p-type dopants, such as lithium bis(trifluoromethylsulfonyl)-imide (Li-TFSI ), are often required, in order to increase the conductivity ${ }^{15-17}$. These additives have been shown to negatively impact the device stability, and elimination of this requirement is beneficial ${ }^{18}$.
Herein we report a new, simple, HTM, comprised of a central difluorinated phenyl ring, tetra-substituted with paramethoxydiarylamine groups (DFTAB). Devices fabricated using DFTAB demonstrated a stabilised PCE of $>10 \%$, have a higher energy absorption cutoff than devices utilizing the ubiquitous spiro-OMeTAD, and offer the potential to be used without the addition of ionic additives.

Scheme 1. One- step synthetic route for DFTAB
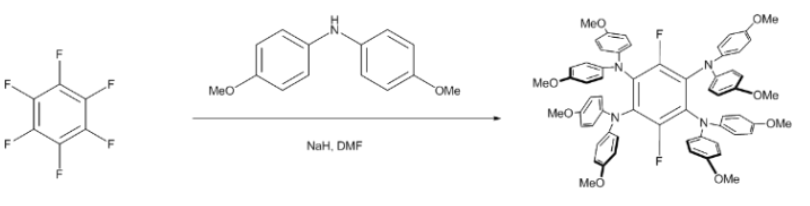

DFTAB

DFTAB, namely 3,6-difluoro- $N^{1}, N^{1}, N^{2}, N^{2}, N^{4}, N^{4}, N^{5} \cdot N^{5}$ octakis(4-methoxyphenyl)benzene-1,2,4,5-tetraamine was synthesized as shown in Scheme 1. The fundamental objectives for the synthesis of DFTAB were the following: only one synthetic step from inexpensive commercial precursors would be permitted, no use of noble metal catalysts, the chemistry should be high yielding, easily scaleable, and purification can be readily accomplished without scale-limiting column chromatography. The synthesis was carried out in a one pot reaction where 4, 4'-dimethoxydiphenylamine was firstly deprotonated by $\mathrm{NaH}$, followed by nucleophilic aromatic substitution of hexafluorobenzene with in-situ generated amide sodium salt. The product can be recrystallized from common solvents with high $(72 \%)$ yields. Synthetic procedural details and full chemical characterization are provided in the supporting information. Complete structural characterization was accomplished using standard spectroscopic techniques including ${ }^{1} \mathrm{H}$ 
NMR, ${ }^{13} \mathrm{C}$ NMR, HRMS and $\mathrm{x}$-ray and are also included in the supporting information.

The thermal properties were investigated by thermogravimetric analysis (TGA) (Figure S2. in the support information) and differential scanning calorimetry (DSC) (Figure S3. in the support information). The onset of mass loss under nitrogen occurred at around $400{ }^{\circ} \mathrm{C}$, evidence of good thermal stability, while the differential scanning calorimetry (DSC) shows sharp melting peaks at $300{ }^{\circ} \mathrm{C}$, with corresponding crystallisation temperatures of $208{ }^{\circ} \mathrm{C}$ on cooling, illustrating large supercooling effects, due to suppressed organization. a)

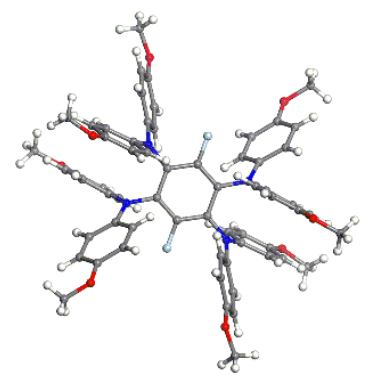

b)

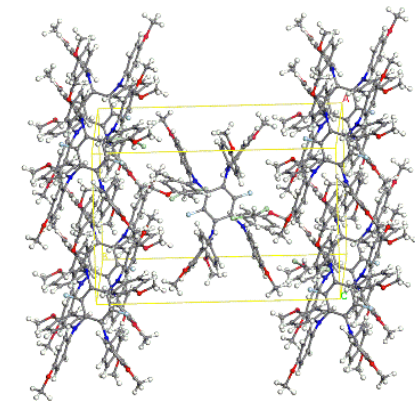

Figure 1. Spatial structure (a) and a unit cell (b) of DFTAB determined by X-ray crystallography (hydrogen atoms omitted for clarity).

Single crystal $x$-ray analysis (Figure 1.) was used to evaluate the molecular conformation and intermolecular packing. DFTAB crystallizes in a monoclinic unit cell, with $\mathrm{P} 2 / \mathrm{n}$ space group. The arylamine aromatic rings attached to the $\mathrm{N}$ atoms twist from each other, with a dihedral angle of $53^{\circ}$ to decrease the electronic repulsion, and enhance the structural stability. The arylamine aromatic rings present almost orthogonal to the central F-phenyl ring, with a dihedral angle of $86^{\circ}$. Packing density calculations reveal that DFTAB has a packing density ratio of 0.6850 based on the occupied volume of $1988.76 \AA^{3}$ and free volume per unit cell of $914.57 \AA^{3}$.

Intramolecular $\pi-\pi$ interactions are not strongly present in the crystal structures, due to the propeller like orientation of the arylamine aromatic rings, and the orthogonal orientation of the central aryl ring. Weak intermolecular interactions between the aryl amine aromatic groups weakly exist, with relatively large $\pi-\pi$ distances ranging from $4.58 \AA$ to $5.92 \AA$. Full structural and packing detail is available in the supporting information.

To better understand the molecular orbital properties of DFTAB, density functional theory (DFT) calculations were carried out with Gaussian09 suite at the B3LYP/6-31G(d) level of theory. Figure 2. illustrates that the highest occupied molecular orbital (HOMO) of DFTAB is delocalized over the entire backbone, whilst the lowest unoccupied molecular orbital (LUMO) is mainly localized on the central difluorinated phenyl core. Having the HOMO strongly extended to the periphery of the molecule is expected to enhance intermolecular hole hopping process and subsequent mobility. a)

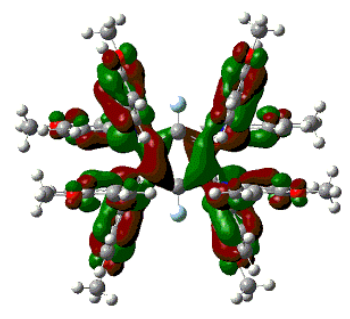

номо b)

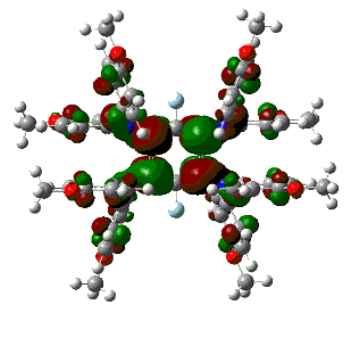

LUMo
Figure 2. Minimum energy conformation of DFTAB calculated using Gaussian (B3LYP/6-31G(d)) to visualize the LUMO and HOMO distribution.

The absorption spectra of thin films of DFTAB and spiroOMeTAD are shown in Figure 3. and the corresponding properties listed in Table 1. DFTAB shows a significant blueshifted onset of absorption and absorption maximum compared to spiro-OMeTAD, with both molecules exhibiting a relatively large bandgap, due to both the twisted conformation, suppressing pi orbital overlap, and the limited number of electrons participating in the conjugated system. The wider bandgap of DFTAB indicates that it would be a more suitable HTM for use in tandem or $\mathrm{MeNH}_{3} \mathrm{PbI}_{3}$ perovskite based devices with reverse illumination architecture.

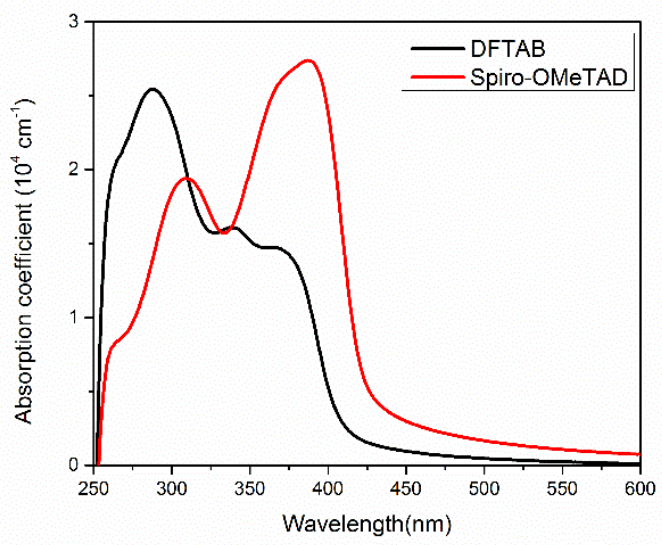

Figure 3. Thin film UV-vis absorption of DFTAB and spiroOMeTAD.

The ionization potential of DFTAB was measured using Photo-Electron Spectroscopy in Air (PESA) and the data shown in Table 1. The resonantly donating nitrogen of the arylamine group, extends electron density to the central core, while the peripheral rings are also electron rich from the electron donation of the methoxy groups. This contributes to a low ionization potential of DFTAB $(5.2 \mathrm{eV})$. The inductively electron withdrawing effect of the two fluorine groups on the central phenyl core counterbalances the electron rich aryl amine groups. 
Table 1. Optical and Electronic Properties of DFTAB

\begin{tabular}{|c|c|c|c|c|}
\hline HTM & $\lambda_{\mathrm{abs}} / \mathrm{nm}$ & $\mathrm{E}_{\text {opt.gap }}{ }^{a}$ & $\begin{array}{l}\text { Ionization } \\
\text { Potential } \\
(\mathrm{eV})^{\mathrm{b}}\end{array}$ & $\begin{array}{l}\text { Electron } \\
\text { Affinity } \\
(\mathrm{eV})^{\mathrm{c}}\end{array}$ \\
\hline DFTAB & 287 & 3.0 & 5.2 & 2.2 \\
\hline $\begin{array}{l}\text { spiro- } \\
\text { OMeTAD }\end{array}$ & 387 & 3.0 & 5.0 & 2.0 \\
\hline \multicolumn{5}{|c|}{ abtained from the onset value of absorption. } \\
\hline $\begin{array}{l}{ }^{b} \text { measured b } \\
\text { system. }\end{array}$ & Phot & Electron & ectroscopy i & Air (PESA) \\
\hline
\end{tabular}

Thin film charge carrier mobilities were measured using the space charge limited current (SCLC) model. The fabricated devices with structure ITO/PEDOT:PSS/HTM/MoOx/Ag were tested under similar conditions as the optimized photovoltaic devices (Table 2.). Hole mobility values were obtained by using the following equation:

$$
J_{S C L C}=\frac{9}{8} \varepsilon_{0} \varepsilon_{r} \mu \frac{V_{i n}^{2}}{L^{3}} e^{\left(\frac{0.89 \beta}{\sqrt{L}} \sqrt{V_{\text {in }}}\right)}
$$

where $\mathrm{J}_{\mathrm{SCLC}}$ is the measured current density, $\varepsilon_{0}$ and $\varepsilon_{\mathrm{r}}$ are the permittivity and material dielectric constant respectively, $\mu$ the charge carrier mobility, $L$ is the film thickness and $\beta$ is the field activation parameter.

Devices showed hole mobility values of $2.9 * 10^{-5} \mathrm{~cm}^{2} \mathrm{~V}^{-1} \mathrm{sec}^{-1}$ (Figure S5. in the support information), a higher value than Spiro-OMeTAD $\left(2.5 * 10^{-5} \mathrm{~cm}^{2} \mathrm{~V}^{-1} \mathrm{sec}^{-1}\right)$ measured under the same conditions.

$\mathrm{MeNH}_{3} \mathrm{PbI}_{3}$ perovskite photovoltaic cells were fabricated with $\quad$ structure: $\quad$ FTO/bl- $\mathrm{TiO}_{2} / \mathrm{mesoporous}$ $\mathrm{TiO}_{2} / \mathrm{MeNH}_{3} \mathrm{PbI}_{3} / \mathrm{HTM} / \mathrm{Au}$. Both HTMs were evaluated with and without tert-butylpyridine and bis(trifluoromethane)sulfonimide lithium salt dopant additives (see supporting information). Typical current-voltage curves for optimised photovoltaic devices are shown in Figure 4.

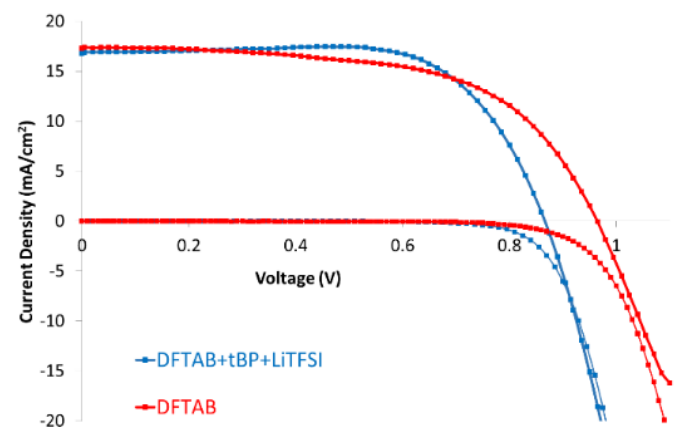

Figure 4. Current voltage characteristics for the best performing $\mathrm{MeNH}_{3} \mathrm{PbI}_{3}$ photovoltaic cells with DFTAB measured under AM 1.5 illumination $\left(100 \mathrm{~mW} \mathrm{~cm}^{-2}\right)$

Devices fabricated with DFTAB+tBP+LiTFSI exhibited an average power conversion efficiency (PCE) of $>10 \%$ in the forward scan direction (Table 2), with a PCE of $8.7 \%$ in the reserve direction showing the cells still have a small amount of hysteresis. This initial performance was lower however than the $15 \%$ reported in literature for equivalent devices fabricated with Spiro-OMeTAD ${ }^{19}$, although, in mitigation, process optimization of Spiro-OMeTAD is much more understood. The HTM layer was optimized with respect to layer thickness by altering the spin speed of deposition, however no further improvements in performance were observed.

To quantify the effect of dopants on the DFTAB in operation, photovoltaic devices were also fabricated without additional additives. In comparison to DFTAB with additives, Figure 4. shows an increased Voc with a near identical Jsc. However there is a decrease in fill factor and the devices show an increased hysteresis effect between scan directions with $7.2 \%$ being achieved in the forward direction but only $4.9 \%$ in the reserve scan direction. This resulted in a lower stabilised PCE of $6 \%$ compared to devices fabricated using additives (Figure S4. in the supporting information). It has been suggested that the addition of oxidising agents such as LiTFSI have a detrimental effect on cell stability, as does the necessity to expose spiro-OMeTAD and cells to oxygen ${ }^{20}$. Therefore the performance of DFTAB without additives represents a promising result when considering the use of this family of molecules in $\mathrm{MeNH}_{3} \mathrm{PbI}_{3}$ photovoltaic devices with long-term stability.

Table 2. Average photovoltaic performance measured in a forward bias $(\mathrm{FB})$ to revere bias $(\mathrm{RB})$ direction and $\mathrm{RB}$ FB.

\begin{tabular}{llllll}
\hline Device & & $\begin{array}{l}\text { Voc } \\
(\mathrm{V})\end{array}$ & $\begin{array}{l}\text { FF } \\
(\%)\end{array}$ & $\begin{array}{l}\text { Jsc } \\
\left(\mathrm{mA} / \mathrm{cm}^{2}\right)\end{array}$ & $\begin{array}{l}\text { PCE } \\
(\%)\end{array}$ \\
\hline $\begin{array}{l}\text { DFTAB } \\
\text { +BP } \\
+ \text { LiTFSI }\end{array}$ & FB-RB & 0.88 & 70.4 & 16.8 & 10.4 \\
& & & & & \\
DFTAB & FB-RB & 0.84 & 54.7 & 15.7 & 7.2 \\
& RB-FB & 0.80 & 42.6 & 14.5 & 4.9 \\
\hline
\end{tabular}

A simple hole transport molecule was designed and synthesized, with only one-step synthesis from inexpensive starting materials. When used as an $\mathrm{HTM}$ in $\mathrm{MeNH}_{3} \mathrm{PbI}_{3}$ perovskite based photovoltaic devices, a stabilised PCE of $10.4 \%$ was achieved and devices exhibit low hysteresis effects. Devices were able to achieve a stabilised PCE of $6 \%$ without the addition of ionic additives (Figure S4. in the support information), which is a promising result when long term device stability is considered. The low-cost, straightforward synthetic method, makes this class of molecules promising candidates for hole transport materials in the large scale application of perovskite solar cells.

\section{EXPERIMENTAL SECTION}


All compounds were characterized by ${ }^{1} \mathrm{H}$ NMR, ${ }^{13} \mathrm{C}$ NMR on a Bruker Avance III Ultrashielded 600 Plus instrument. High-resolution mass spectrometry (HRMS) data was recorded using a Thermo Scientific - LTQ Velos Orbitrap MS in positive atmospheric pressure photoionization (+APPI) mode. UV-Vis spectra were recorded in a Varian Cary 100 spectrophotometer. Thermogravimetric analysis (TGA) was performed under $\mathrm{N}_{2}$ using Bruker TGA-IR TG209F1 with a ramp of $10{ }^{\circ} \mathrm{C} / \mathrm{min}$. Differential Scanning Calorimetry (DSC) was run on DSC-204F1-phoenix. X-ray diffraction measurement of DFTAB was collected on a Bruker D8 Venture diffractometer with PHOTON 100 CMOS detector with an microfocus source (Mo Ka radiation, $1=0.71073 \AA$ ). The computing cell refinement and data reduction was processed using APEX2 software. Packing density calculations were from Material Studio software package (Connolly surface). A Keithley 2400 was employed to obtain the $\mathrm{J} / \mathrm{V}$ characteristics and hole mobility values The perovskite photovoltaic cells were fabricated with structure:

FTO/bl- $\mathrm{TiO}_{2} /$ mesoporous- $^{-}$ $\mathrm{TiO}_{2} / \mathrm{MeNH}_{3} \mathrm{PbI}_{3} / \mathrm{HTM} / \mathrm{Au}$. The details of the device manufacture were listed in the support information.

\section{ASSOCIATED CONTENT}

\section{Supporting Information.}

This material is available free of charge via the Internet at http://pubs.acs.org."

Synthetic details of DFTAB, ${ }^{1} \mathrm{H}$ NMR and ${ }^{13} \mathrm{CNMR}$ of DFTAB, TGA curve of DFTAB, DSC trace of DFTAB, Device fabrication details, Current-Voltage (JV) Measurements, crystallographic table, CIF file of DFTAB (CIF).

\section{AUTHOR INFORMATION}

\section{Corresponding Author}

*Email: hu.chen@kaust.edu.sa

\section{Author Contributions}

The manuscript was written through contributions of all authors. All authors have given approval to the final version of the manuscript.

Notes

The authors declare no competing financial interest.

\section{ACKNOWLEDGMENT}

We acknowledge funding from EPSRC Project EP/G037515/1 and EP/I019278/1, EC FP7 Project SC2 (610115), EC FP7 Project ArtESun (604397), and EC FP7 POLYMED (612538) for the financial support.

\section{REFERENCES}

(1) Kojima, A.; Teshima, K.; Shirai, Y.; Miyasaka, T. Organometal halide perovskites as visible-light sensitizers for photovoltaic cells. $J$. Am. Chem. Soc. 2009, 131, 6050-6051.

(2) Kim, H.-S.; Lee, C.-R.; Im, J.-H.; Lee, K.-B.; Moehl, T.; Marchioro, A.; Moon, S.-J.; Humphry-Baker, R.; Yum, J.-H.; Moser, J. E.; Grätzel, M.; Park, N.-G. Lead Iodide Perovskite Sensitized AllSolid-State Submicron Thin Film Mesoscopic Solar Cell with Efficiency Exceeding 9\%. Sci. Rep. 2012, 2, 591.

(3) Burschka, J.; Pellet, N.; Moon, S.-J.; Humphry-Baker, R.; Gao, P.; Nazeeruddin, M. K.; Gratzel, M. Sequential deposition as a route to high-performance perovskite-sensitized solar cells. Nature 2013, 499, 316-319.
(4) Zhou, H.; Chen, Q.; Li, G.; Luo, S.; Song, T.-B.; Duan, H.-S ; Hong, Z.; You, J.; Liu, Y.; Yang, Y. Interface engineering of highly efficient perovskite solar cells. Science 2014, 345, 542-546.

(5) Lee, M. M.; Teuscher, J.; Miyasaka, T.; Murakami, T. N.; Snaith, H. J. Efficient Hybrid Solar Cells Based on MesoSuperstructured Organometal Halide Perovskites. Science 2012, 338, 643-647.

(7) Nie, W.; Tsai, H.; Asadpour, R.; Blancon, J.-C.; Neukirch, A. J.; Gupta, G.; Crochet, J. J.; Chhowalla, M.; Tretiak, S.; Alam, M. A.; Wang, H.-L.; Mohite, A. D. High-efficiency solution-processed perovskite solar cells with millimeter-scale grains. Science 2015, 347, 522-525.

(8) Eperon, G. E.; Stranks, S. D.; Menelaou, C.; Johnston, M. B.; Herz, L. M.; Snaith, H. J. Formamidinium lead trihalide: a broadly tunable perovskite for efficient planar heterojunction solar cells. Energy Environ. Sci. 2014, 7, 982-988.

(9) Docampo, P.; Ball, J. M.; Darwich, M.; Eperon, G. E.; Snaith, H.J. Efficient organometal trihalide perovskite planar-heterojunction solar cells on flexible polymer substrates. Nat. Commun. 2013, 4, 2761.

(10) Yu Z.; Sun L. Recent Progress on Hole-Transporting Materials for Emerging Organometal Halide Perovskite Solar Cells. Adv. Energy Mater. 2015, 5, 1500213.

(11) Gheno, A.; Vedraine, S.; Ratier, B.; Bouclé, J. $\pi$-Conjugated Materials as the Hole-Transporting Layer in Perovskite Solar Cells. Metals 2016, 6, 21.

(12) Liu, J.; Wu, Y.; Qin, C.; Yang, X.; Yasuda, T.; Islam, A.; Zhang K.; Peng, W.; Chen W.; Han L. A dopant-free holetransporting material for efficient and stable perovskite solar cells. Energy Environ. Sci. 2014, 7, 2963-2967.

(13) Li, H.; Fu, K.; Hagfeldt, A.; Grätzel, M.; Mhaisalkar, S. G.; Grimsdale, A. C. A Simple 3, 4-Ethylenedioxythiophene Based HoleTransporting Material for Perovskite Solar Cells. Angew. Chemie. Int. $E d .$, 2014, 53, 4085-4088.

(14) Heo, J. H.; Im, S. H.; Noh, J. H.; Mandal, T. N.; Lim, C. S.; Chang, J. A.; Lee, Y. H.; Kim, H.; Sarkar, A.; K., N.; Gratzel M.; Seok, S. Il. Efficient inorganic-organic hybrid heterojunction solar cells containing perovskite compound and polymeric hole conductors. Nat Phot. 2013, 7, 486-491.

(15) Zhang, H.; Shi, Y.; Yan, F.; Wang, L.; Wang, K.; Xing, Y.; Dong Q.; Ma, T. A dual functional additive for the HTM layer in perovskite solar cells. Chem. Commun. 2014, 50, 5020-5022.

(16) Noh, J. H.; Jeon, N. J.; Choi, Y. C.; Nazeeruddin, M. K.; Grätzel, M.; Seok, S. Il. Nanostructured TiO2/CH3NH3PbI3 heterojunction solar cells employing spiro-OMeTAD/Co-complex as holetransporting material. J. Mater. Chem. A 2013, 1, 11842-11847.

(17) Abate, A.; Leijtens, T.; Pathak, S.; Teuscher, J.; Avolio, R.; Errico, M. E.; Kirkpatrik, J.; Ball, J. M.; Docampo, P.; McPherson I.; Snaith, H. J. Lithium salts as "redox active" p-type dopants for organic semiconductors and their impact in solid-state dye-sensitized solar cells. Phys. Chem. Chem. Phys. 2013, 15, 2572-2579.

(18) Abate, A.; Leijtens, T.; Pathak, S.; Teuscher, J.; Avolio, R.; Errico, M. E.; Kirkpatrik, J.; Ball, J. M.; Docampo, P.; McPherson I.; Snaith, H. J. Lithium salts as "redox active" p-type dopants for organic semiconductors and their impact in solid-state dye-sensitized solar cells. Phys. Chem. Chem. Phys. 2013, 15, 2572-2579.

(19) Bi, D.; Tress, W.; Dar, M. I.; Gao, P.; Luo, J.; Renevier, C.; Schenk, K.; Abate, A.; Giordano, F.; Baena, C. J.-P.; Decoppet, J.-D.; Zakeeruddin, S. M.; Nazeeruddin, M. K.; Grätzel M.; Hagfeldt, A. Efficient luminescent solar cells based on tailored mixed-cation perovskites. Sci. Adv. 2016, 2, e1501170.

(20) Nguyen, W. H.; Bailie, C. D.; Unger, E. L.; McGehee, M. D. Enhancing the hole-conductivity of spiro-OMeTAD without oxygen or lithium salts by using spiro (TFSI) 2 in perovskite and dyesensitized solar cells. J. Am. Chem. Soc. 2014, 136, 10996-11001. 


\section{Table of Contents}

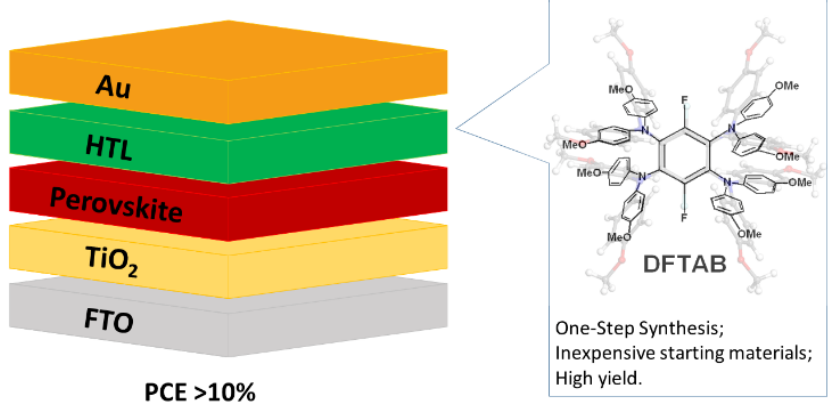

